\title{
Production and Release of Asexual Sporangia in Plasmopara viticola
}

\author{
Tito Caffi, Giovanna Gilardi, Matteo Monchiero, and Vittorio Rossi
}

First and fourth authors: Università Cattolica del Sacro Cuore, Istituto di Entomologia e Patologia vegetale, I-29122 Via. E. Parmense 84, Piacenza, Italy; and second and third authors: Agroinnova, University of Torino, Via Leonardo da Vinci, 44, 100095 Grugliasco, Torino, Italy. Accepted for publication 27 August 2012.

\begin{abstract}
Caffi, T., Gilardi, G., Monchiero, M., and Rossi, V. 2013. Production and release of asexual sporangia in Plasmopara viticola. Phytopathology 103:64-73.

To study the influence of environmental conditions on sporulation of Plasmopara viticola lesions under vineyard's conditions, unsprayed vines were inspected every second or third day and the numbers of sporulating and nonsporulating lesions were counted in two North Italy vineyards in 2008 to 2010. Infected leaves were removed so that only fresh lesions were assessed at each field assessment. Sporulation was studied at two scales, across field assessments and across the seasonal population of lesions. Frequencies of sporulating lesions were positively correlated with the numbers of moist hours in the preceding dark period (i.e., the number of hours between 8:00 p.m. and 7:00 a.m. with relative humidity $\geq 80 \%$, rainfall $>0 \mathrm{~mm}$, or wetness duration $>30 \mathrm{~min}$ ). In a receiver operating characteristic analysis, predicted sporulation based on the occurrence of $\geq 3$ moist hours at night provided overall accuracy of 0.85 . To study the
\end{abstract}

ABSTRACT time course of sporulation on lesions which were not washed by rainfall, numbers of sporangia produced per square millimeter of lesion were estimated on individual cohorts of lesions over the whole infectious period. The numbers of sporangia per square millimeter of lesion increased rapidly during the first 4 days after the beginning of sporulation and then tapered off prior to a halt; the time course of cumulative sporangia production by a lesion followed a monomolecular growth model $\left(R^{2}=0.97\right)$. The total number of sporangia produced by a square millimeter of lesion increased as the maximum temperature decreased and moist hours in the dark increased. To study the release pattern of the sporangia, spore samplers were placed near grapevines with sporulating lesions. Airborne sporangia were caught in $91.2 \%$ of the days over a wide range of weather conditions, including rainless periods. The results of this study provide quantitative information on production of $P$. viticola sporangia that may help refine epidemiological models used as decision aids in grape disease management programs.
The life cycle of Plasmopara viticola (Berk. \& M. A. Curtis) Berl. \& De Toni, the causal agent of grapevine downy mildew, consists of sexual and asexual cycles that occur throughout the grapevine growing season (39). Overwintered oospores progressively germinate in the spring and produce macrosporangia, which release zoospores as primary inoculum. The production of primary inoculum can continue until the end of vine flowering and beyond (16). Zoospores are rain splashed onto vine tissues, which they may infect. Early symptoms appear as yellow lesions on the upper leaf surface. Within 5 to 10 days after the initial infection, sporangiophores and sporangia are produced and form a dense, raised, white-cottony mildew on the underside of lesions. Sporangia become airborne and release clonal zoospores as secondary inoculum. Secondary disease cycles occur under suitable infection conditions after sporulation (36).

Most of our knowledge on sporulation of $P$. viticola has been derived from environmentally controlled experiments. These studies showed that sporulation depends on light, relative humidity $(\mathrm{RH})$, and temperature. Sporulation of $P$. viticola is inhibited by light (6) and, therefore, occurs at night $(31,42,44)$. High RH, which often occurs at night, is required for sporulation $(3,26)$. Temperatures $<10^{\circ} \mathrm{C}$ and $>30^{\circ} \mathrm{C}$ are conducive for sporulation $(24,26,38)$. Although Gilles (17) pointed out that conditions required for sporangia production in a vineyard could differ from those reported under controlled conditions, this has not been sufficiently investigated, partly because studying sporulation in situ is difficult (41). Therefore, the first aim of the present work

Corresponding author: V. Rossi; E-mail address: vittorio.rossi@unicatt.it

http://dx.doi.org/10.1094/PHYTO-04-12-0082-R

(C) 2013 The American Phytopathological Society was to investigate the influence of weather on sporulation of $P$. viticola under a vineyard's conditions.

Sporangia production on lesions was previously studied by inducing sporulation on individual lesions, washing off the sporangia in such a way that rainfall effects would be simulated, counting the sporangia in the collected washing water, and repeating this procedure for several sporulation cycles. This work showed that individual foliar lesions sporulated repeatedly, some of them remaining viable and productive for up to 2 to 3 months $(19,45)$. However, sporangial production over sequential "rainfall" episodes progressively decreased $(19,22)$, which was associated with increased necrosis of the lesion until only sparse, marginal sporulation was supported (22). Such results are important to understand the contribution of individual lesions to downy mildew epidemics but do not provide information on the time course of sporangial production on a lesion in rainless periods. Therefore, the second aim of the present work was to investigate the time course of sporulation of $P$. viticola on individual lesions during rainless periods and its relationships with weather conditions other than rainfall.

It is commonly stated that sporangia become airborne primarily in the presence of rain or dew (16). Data from spore samplers in vineyards indicate that sporangia are only released during rainfall events $(3,21)$. However, release of sporangia by wind cannot be excluded (17). Wind-tunnel experiments (4) showed that sporangia were released when wind speed was $>9 \mathrm{~m} \mathrm{~s}^{-1}$. Further, $P$. viticola sporangia were found to be part of the airborne microflora of the vineyards even during periods without rain $(1,4,8,12,13$, $15,29,34)$. Previous studies did not allow the analysis of environmental effects on sporulation and sporangial release separately; in other words, increased spore release with rainfall could be due to rain enhancing sporulation rather than to the direct effect of rain on release itself. Thus, the third aim of the present work was 
to attempt to separate the effect of weather on the release of $P$. viticola sporangia from weather effect on sporangia production. Therefore, the release pattern of sporangia was studied in the immediate proximity of sporulating lesions, which served as a continuous source of sporangia.

\section{MATERIALS AND METHODS}

Production of sporangia in vineyards in situ. To study the influence of environmental conditions on sporulation of $P$. viticola lesions under a vineyard's conditions, two vineyards located at Grugliasco and Neive in Piedmont (North Italy) were monitored over a 3-year period (2008 to 2010). The Grugliasco vineyard was planted in 2001 with 'Moscato' vines trained on a Guyot trellis system and spaced $1 \mathrm{~m}$ along the row and $2 \mathrm{~m}$ between rows. This vineyard is located at the base of the Alps, $260 \mathrm{~m}$ above sea level, and has environmental conditions that are usually very favorable for downy mildew. The Neive vineyard was planted in 1965 with 'Barbera' plants trained on a Guyot trellis system and spaced $1 \mathrm{~m}$ along the row and $2 \mathrm{~m}$ between rows. This vineyard is located on a hill at $280 \mathrm{~m}$ above sea level. Downy mildew epidemics are usually less severe at Neive than at Grugliasco.

One 150-vine section of each vineyard was not sprayed against downy mildew each year (different plants were used each year). Starting from approximately mid-May, when shoots were at the first unfolded leaves stage (6), plants were inspected every second or third day to (i) estimate the prevalent growth stage (i.e., $>50 \%$ of the vines), (ii) count the number of leaves with downy mildew lesions, and (iii) count the number of downy mildew lesions with and without typical sporulation signs. The presence of sporangiophores and sporangia was determined by careful examination of each lesion with a magnification hand lens $(\times 5)$; when the presence of sporangiophores and sporangia was uncertain, lesions were examined with a microscope in the laboratory. Once a diseased leaf was examined, it was removed in order to enable the detection of new lesions at each assessment. Observations ended between mid-June and late July, depending on the vineyard and its growth rate.

Data for air temperature $\left(\mathrm{T},{ }^{\circ} \mathrm{C}\right), \mathrm{RH}(\%)$, total rainfall $(\mathrm{R}, \mathrm{mm})$, and wetness duration (WD, min) were registered hourly by stations of the Regional Agrometerological Service (http://www. regione.piemonte.it/agri/set_fitosanit/agrometeo/index.htm) positioned at the edges of the vineyards. Weather data were used to calculate the following variables on a daily time scale (a climatic day operationally starting at 1:00 p.m. of one day and finishing at 12:00 a.m. the following day): average, maximum, and minimum $\mathrm{T}$; average RH; total R; total WD (in hours); average vapor pressure deficit (VPD, hPa); number of hours with $\mathrm{RH} \geq 80,85$, and 90\%; and number of hours between 8:00 p.m. and 07:00 a.m. with $\mathrm{RH} \geq 80 \%, \mathrm{R}>0$, and WD $>0.5 \mathrm{~h}$ (hereafter named "dark, moist hours"). For each time window between two field assessments, the following variables were calculated: average $\mathrm{T}$ and $\mathrm{RH}$; sum of R, WD, and hours with $\mathrm{RH} \geq 80,85$, and $90 \%$; and highest value of maximum T, VPD, and number of dark moist hours.

The relationships between these weather variables and sporulation frequency (i.e., the number of occurrences of sporulating lesions per time unit) of $P$. viticola in the field were investigated at two time scales: across field assessments and across populations of lesions (i.e., the entire number of seasonal lesions), with three analyses. All statistical analyses were carried out using PASW Statistic 18 (IBM, Armonk, NY). In the first analysis, each field assessment when downy mildew lesions were detected was classified as " 0 " if sporulating lesions were absent or as " 1 " if sporulating lesions were present (regardless of the frequency of sporulating lesions). Differences in the weather variables between the two groups (field assessments with or without sporulating lesions) were determined using a $t$ test. In the second analysis, the
Pearson's correlation coefficients were calculated between the weather variables and the frequency of downy mildew lesions with sporangia at each field assessment. In the third analysis, weather variables were considered as possible predictors of sporulation in a receiver operating characteristic (ROC) analysis (18). This is a statistical method for measuring the accuracy of predictors and it is, basically, a plot of the true positive proportion (TPP, or sensitivity) of the prediction as a function of the false positive proportion (FPP, or 1-specificity) for different cut-off points of each weather variable. For instance, the cut-off points for dark moist hours were $=0 \mathrm{~h}$ (i.e., no dark moist hours between two assessments), $\geq 1$ (at least 1 moist hour between two assessments), $\geq 2 \mathrm{~h}, \geq 3 \mathrm{~h}, \geq 4 \mathrm{~h}, \geq 5 \mathrm{~h}, \geq 6 \mathrm{~h}, \geq 7 \mathrm{~h}, \geq 8 \mathrm{~h}, \geq 9 \mathrm{~h}, \geq 10 \mathrm{~h}$, and $\geq 11 \mathrm{~h}$. Each point on the ROC curve represents a sensitivity/specificity pair corresponding to a particular cut-off point; the closer the ROC curve is to the upper left corner of the plot, the higher the overall accuracy of the test (i.e., the ratio between the number of cases assigned to the correct class and the number of cases that actually belong to that class) (46). For every possible cut-off point, the proportion of assessments correctly classified as positive (TPP) or negative (true negative proportion [TNP]) or wrongly classified as negative (false negative proportion [FNP]) or positive (FPP) was calculated. The area under the ROC curve (AUROC) and its 95\% confidence interval were calculated to measure how well a weather variable distinguished between the two groups (sporulation or no sporulation). The AUROC lies into the interval $[0.5,1]$, and a larger AUROC indicates better performance. The $P$ value was calculated as the probability that the AUROC is different from the null hypothesis (i.e., that AUROC = 0.5 ) (the ROC curve coincides with the no-information line with coordinates of 0,0 and 1,1) and that the variable under study does not distinguish between the two groups.

Time course of sporulation on individual lesions. To study the sporulation dynamic on lesions during rainless periods, 7-year-old potted plants of Vitis vinifera Barbera at the University campus of Piacenza (Emilia-Romagna, North Italy) and on a portion of a Moscato vineyard at Grugliasco were artificially inoculated 10 times in 2008 to 2010. For each inoculation, the four youngest, fully expanded leaves of 20 shoots were inoculated; five 10- $\mu$ l droplets of a suspension containing at least $1 \times$ $10^{4}$ sporangia/ $\mu \mathrm{l}$ were deposited on the abaxial surface of each leaf. The inoculum was prepared by gently shaking, in distilled water, sporulating leaf disks which had been inoculated in petri dishes with a mixture of isolates originally obtained from six vineyards in 2007. The inoculum has been maintained on potted Barbera vines in a glasshouse.

All inoculations were performed in late afternoon. After inoculation, leaves were placed in polyethylene bags that were moistened and sealed to prevent drying of the inoculum droplets. Polyethylene bags were removed $12 \mathrm{~h}$ after inoculation. Leaves were observed daily to determine when downy mildew lesions first appeared and when sporulation signs first appeared on the underside of the foliar lesions. At that time, sporulating lesions were labeled and considered as a cohort.

Two to three labeled leaves were excised daily (or occasionally every other day), and the adaxial and abaxial leaf surfaces were photographed with a high-resolution digital camera. The images were analyzed with a digital image analysis software (Assess 2, Image Analysis Software for Plant Disease Quantification; American Phytopathological Society Press, St. Paul, MN) to estimate the lesion size (in square millimeters) on the adaxial surface and the area occupied by sporangiophores (in square millimeters) on the abaxial surface; the area occupied by sporangiophores was considered to be the area with white, fresh mildew. The fraction (\%) of lesion area with sporulation was then calculated by dividing the lesion area by the sporulating area. After they were photographed, single lesions were cut and agitated for $2 \mathrm{~min}$ in $2 \mathrm{ml}$ of distilled water. The resulting suspension was placed in an 
incubator at $20^{\circ} \mathrm{C}$ for $24 \mathrm{~h}$ in the dark. The number of sporangia/ml of suspension was then estimated with a hemocytometer; a total of nine hemocytometer chambers were examined for each lesion. Sporangia were scored as ungerminated and germinated (i.e., empty) (29) per square millimeter of lesion. The percentage of sporangia that had germinated was then calculated.

For six inoculations, the observations were stopped at the end of the sporulation period (i.e., at the end of the first infectious period), i.e., when no sporangia were observed for at least two consecutive days on the cohort of lesions that had produced sporangia. For four inoculations, lesions which completed a first sporulation period were washed with water as described by Kennelly et al. (22) and then observed during the second and, in one case, the third sporulation period. Sporulation periods were then partitioned in two groups: (i) first sporulation periods after inoculation; and (ii) second or third sporulation periods after inoculation. The duration of the sporulation period, percentage of the lesion area with sporangia, number of sporangia produced per square millimeter of lesion per day, and percentage of germinated sporangia were calculated for the two groups. Differences between the two groups were determined using a $t$ test. Before analysis, percentages and numbers were transformed as arcsine and natural logarithm, respectively, to stabilize variances. Uniformity of variances was confirmed using the Levene test (27).

For investigation of sporangial production over the infectious period of a cohort of lesions, the total number of sporangia produced per square millimeter of lesion over the entire infectious period was calculated and used to scale the daily production of sporangia. The daily cumulative proportion of sporangia was used as the dependent variable $(Y)$ in a nonlinear regression, where the numerical order of the day $(X)$ of the sporulation event was the independent variable. A monomolecular growth curve was used in the following form: $Y=1-(1-a) e^{(-b X)}$, where $a$ is the theoretical production when $X=0$ and $b$ is the rate of sporangia production. Parameters were estimated using the Levenberg-Marquardt iteration algorithm, using a reduction criterion of $1.00 \mathrm{E}-08$ for the sum of squares to stop iteration.

Pearson's correlation coefficients were calculated between either the duration of the infectious period or the total numbers of sporangia produced by lesions over the whole infectious period (natural logarithm of number of sporangia +1 ) and the following weather variables calculated using the daily data of the sporulation period: average, minimum, and maximum temperature and $\mathrm{RH}$; sum of rainfall, and ratios of hours with $\mathrm{RH} \geq 80 \%$ and moist hours in the dark (as defined in study 1) over the total hours of the sporulation period. Weather data were recorded by weather stations (SIAP38-40 at Grugliasco and Vantage Pro, Davis Instruments, USA, at Piacenza) placed near the potted plants.

Release of sporangia. To study the pattern of sporangia release in the proximity of sporulating lesions, 7-day recording volumetric spore samplers (Lanzoni VPPS-2000, Bologna, Italy) were operated at Grugliasco and Piacenza in 2009 and 2010. At Grugliasco, one spore sampler was installed within two rows of the previously described Moscato vineyard; the two rows were not sprayed against downy mildew. The spore sampler was operated from 2 July to 17 October 2009 and from 16 June to 3 October 2010, when several downy mildew lesions were present and sporangia production was consistent.

At Piacenza, eight potted plants of Barbera (6 years old and $2 \mathrm{~m}$ tall) with sporulating downy mildew lesions were evenly spaced along the edge of a 6-by-6-m square. One spore sampler was located at the center of this square between 6 May and 11 July 2009, 24 September and 19 October 2009, and 24 August and 19 October 2010. During the above periods, the eight potted plants served a continuous source of sporangia. Plants were replaced when necessary with new plants that had been inoculated with $P$. viticola and that produced abundant sporangia. Inoculum was prepared as previously described, and the inoculations were performed in late afternoon by misting plants with the sporangial suspension until run-off. Plants were covered overnight with polyethylene bags after inoculation to favor infection, and again when lesions appeared to favor sporulation.

Spore samplers were operated continuously. The samplers were adjusted to sample air at 10 liters $/ \mathrm{min}$ at $150 \mathrm{~cm}$ above the ground. A tape coated with silicon solution (5\%) served as the trapping surface and was removed at weekly intervals. Four equidistant transects across the long axis of the tape at intervals of $4 \mathrm{~mm}$ (equivalent to $2 \mathrm{~h}$ ) were examined microscopically at $\times 675$ magnification. The number of $P$. viticola sporangia observed in each 2-h transect was corrected for the proportion of tape examined and the volume of air sampled: the number was then expressed as the number of sporangia per cubic meter of air in $2 \mathrm{~h}$. The spore counts were not adjusted for trap efficiency.

\section{RESULTS}

Production of sporangia in vineyards. In total, 100 field assessments were performed in the two vineyards between 2008 and 2010 (Table 1). These field assessments started at growth stage 11 (first leaf unfolded) in all vineyards and ended at stage 71 (fruit set) in 2008, and between stage 79 (most berries touching) and stage 81 (beginning of ripening) in 2009 and 2010. In 58 assessments (58.0\% of total assessments), there were new downy mildew lesions; in all, 61,921 lesions were counted. In 44 assessments $(75.9 \%$ of the field assessments when lesions were observed), lesions produced sporangiophores; 14,761 sporulating lesions were counted (23.8\% of total lesions). The average percentage of lesions with sporangiophores was higher in 2008 (41.3\% for the two vineyards) than in 2009 (32.3\%) and 2010 (6.7\%) (Table 1). Differences between sequential field assessments were detected in each vineyard in each year (Fig. 1).

This study included a wide range of weather conditions (Table 2 ). Conditions were dryer in assessments when no sporulation was observed; rainfall, number of hours with $\mathrm{RH} \geq 80 \%$, and number of dark moist hours were all greater when there was sporulation (Table 2). Sporulation was not statistically related to

TABLE 1. Sporulation in downy mildew lesions during field assessments in two vineyards in North Italy in 2008 to 2010

\begin{tabular}{|c|c|c|c|c|c|c|c|}
\hline \multirow[b]{2}{*}{ Vineyard, year } & \multicolumn{6}{|c|}{ Number of } & \multirow[b]{2}{*}{$\begin{array}{l}\text { Sporulating } \\
\text { lesions }(\%)\end{array}$} \\
\hline & $\begin{array}{c}\text { Total } \\
\text { assessments }\end{array}$ & $\begin{array}{l}\text { Assessments } \\
\text { with lesions }^{\mathrm{a}}\end{array}$ & $\begin{array}{l}\text { Assessments with } \\
\text { sporulating lesions }^{b}\end{array}$ & $\begin{array}{c}\text { Diseased } \\
\text { leaves }\end{array}$ & $\begin{array}{c}\text { Total } \\
\text { lesions }\end{array}$ & $\begin{array}{l}\text { Sporulating } \\
\text { lesions }\end{array}$ & \\
\hline Grugliasco 2008 & 10 & 7 & 7 & 6,439 & 23,557 & 9,832 & 41.7 \\
\hline Neive 2008 & 10 & 6 & 5 & 1,627 & 3,412 & 1,394 & 40.9 \\
\hline Grugliasco 2009 & 18 & 16 & 15 & 913 & 1,663 & 657 & 39.5 \\
\hline Neive 2009 & 16 & 8 & 6 & 292 & 437 & 110 & 25.2 \\
\hline Grugliasco 2010 & 23 & 15 & 10 & 12,475 & 32,832 & 2,767 & 8.4 \\
\hline Neive 2010 & 23 & 6 & 1 & 19 & 20 & 1 & 5.0 \\
\hline
\end{tabular}

a New lesions were observed on each field assessment because diseased leaves were removed after examination.

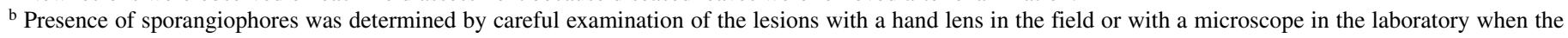
field determination was uncertain. 
temperature (Table 2). The frequency of sporulating lesions was positively correlated with the number of hours with $\mathrm{RH} \geq 80 \%$ $(P=0.036, r=0.28, n=58)$ and number of dark moist hours $(P<$ $0.001, r=0.52, n=58$ ) (Table 2). The frequency of sporulating lesions increased as the number of dark moist hours preceding the assessments increased (Fig. 2). For instance, this frequency was $0.6 \%$ with no moist hours, $13.5 \%$ with $1 \mathrm{~h}$, and $43.8 \%$ with 11 or $12 \mathrm{~h}$.

Based on the ROC analysis, the number of dark moist hours was the best sporulation predictor (Table 3). The ROC curve

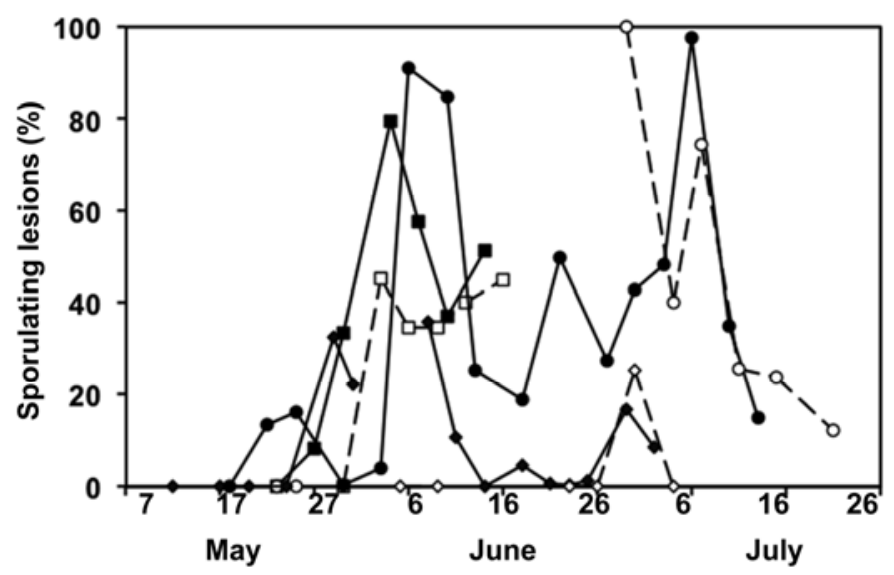

Fig. 1. Percentages of downy mildew lesions with sporangiophores observed in the vineyards of Grugliasco (black symbol) and Neive (white symbol), North Italy, in 2008 (square), 2009 (circle), and 2010 (diamond). Field assessments were performed every 2 or 3 days; assessments started at growth stage 11 in all the years (early May) and stopped at growth stage 71 (mid-June), stage 79 (mid-July), and stage 81 (mid-July) in 2008, 2009, and 2010, respectively. No downy mildew lesions were found in field assessments without symbols. strongly departed from the no-information line of the sensitivity versus 1-specificity plot (i.e., no value predictor) and approached the upper left corner of the plot, with the maximum distance between the ROC curve and the no-information line at the cut-off point of $\geq 3 \mathrm{~h}$ moist hours in the dark (Fig. 3). The AUROC was 0.816 , which was significantly $(P<0.001)$ larger than 0.5 .

When $\geq 3$ moist hours in the dark was used as the predictor of sporulation, 39 sporulation events and 10 no-sporulation events were correctly predicted; 5 sporulation events were predicted that did not actually occur (i.e., sporulation overestimated) and 4 sporu-

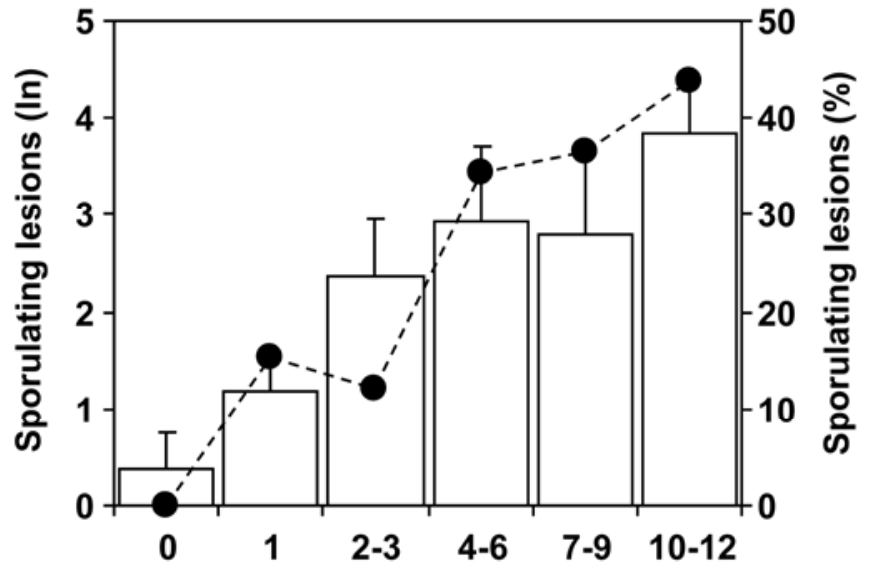

Number of dark moist hours

Fig. 2. Number of downy mildew lesions with sporangiophores (i.e., sporulating) (bars, in natural logarithm) and percentage of these lesions relative to the total number of lesions observed (circles) in two vineyards of North Italy in 2008 to 2010 as a function of the number of moist hours in the dark period preceding the observation. Whiskers indicate the standard errors for the bars.

TABLE 2. Weather data from two vineyards in North Italy in 2008 to 2010 during periods with and without sporulation on downy mildew lesions, and the correlation coefficient between weather variables and the frequency of lesions with sporulation

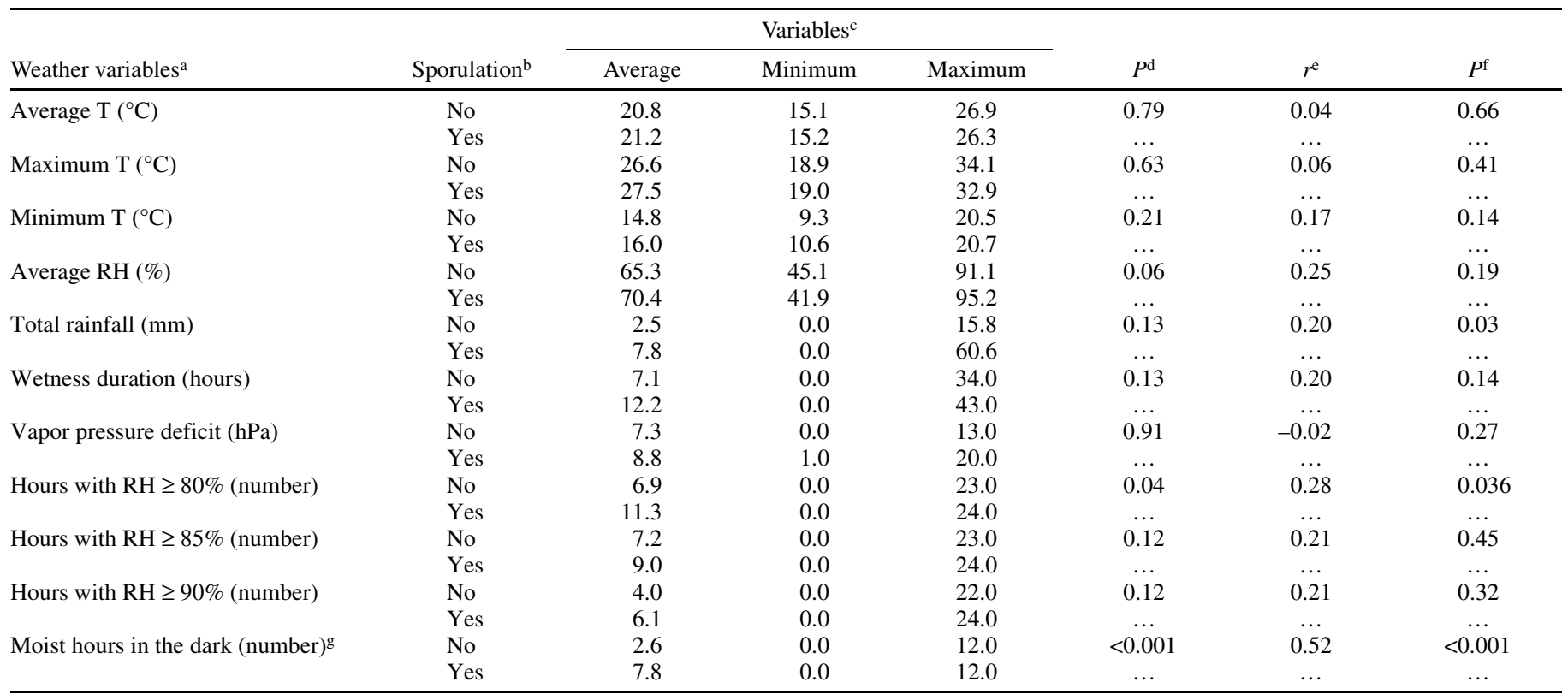

${ }^{a}$ Weather variables were calculated in the time period between two field assessments; $\mathrm{T}=$ air temperature and $\mathrm{RH}=$ relative humidity.

${ }^{\mathrm{b}}$ Lesions were considered sporulating when white, raised, cottony mildew developed on the abaxial leaf surface; lesions were observed with a hand lens in the field or with a microscope in the laboratory when the field determination was uncertain.

c Average, minimum, and maximum refer to the weather variables.

${ }^{\mathrm{d}}$ Probability level of the $t$ test for differences between the two sporulation groups (no or yes).

e Pearson's correlation coefficient.

${ }^{\mathrm{f}}$ Probability level of $r(n=58)$.

g Number of hours in the dark (i.e., between 8:00 p.m. and 7:00 a.m.) with $\mathrm{RH} \geq 80 \%$, rain $>0 \mathrm{~mm}$, or wetness duration $>30 \mathrm{~min}$. 
lation events occurred that had not been predicted (i.e., sporulation underestimated). In one of the four underestimated sporulation events (23 June 2010 at Grugliasco), conditions were dry but 13 of the 2,656 total lesions were sporulating; in the 2 days following the previous assessment (on 21 June), $\mathrm{RH}$ was never $\geq 80 \%$, average $\mathrm{RH}$ was $50.5 \%$, and $\mathrm{T}$ was 13.4 to $26.3^{\circ} \mathrm{C}$.

Because of these four underestimated events, the $\mathrm{FNP}=0.09$; as a consequence, the occurrence of 81 sporulating lesions $(0.6 \%$ of the total sporulating lesions) was incorrectly predicted. Sensitivity was TPP $=0.91$, specificity was TNP $=0.67$, and the overall accuracy was 0.85 . With $\mathrm{LR}(+)$ (likelihood ratio of a positive prediction, TPP/FPP) $=5.74$ and $\mathrm{LR}(-)$ (likelihood ratio of a negative prediction, FNP/TNP) $=0.14$, the posterior probabilities that there was sporulation when sporulation was predicted or not predicted were 0.89 and 0.29 , respectively.

Duration of infectious period and production of sporangia. The production of sporangia was studied on 227 downy mildew lesions over 15 sporulation periods; 10 sporulation periods were the first periods after the inoculation of $P$. viticola and 5 were second or third sporulation periods (Table 4). Over the first, second, and third sporulation period, the duration of the infectious period $(P=0.88)$, the percentage of the lesion area with sporulation $(P=0.44)$, the number of sporangia produced per square millimeter of lesion per day $(P=0.06)$, and the percentage of germinated sporangia $(P=0.13)$ did not differ. Therefore, these sporulation periods were pooled for further analysis. All the observed lesions were typical chlorotic ones with no leaf necrosis.

The duration of the infectious period of an individual lesion was $6.7 \pm 0.6$ days (values are means \pm standard error unless notes otherwise), with a minimum of 2 (sporulation period XV) and maximum of 10 (period VIII) days (Table 4); 50\% of cases were in the interval of 6 to 8 days, with a median of 7 days. The duration of infectious period was not related to weather variables during such a period, and no particular weather conditions were associated with end of the infectious period. For instance, in sporulation period VII (Table 4), the first sporangiophores were observed on 17 June and were triggered by high humidity initiated by rainfall (Fig. 4A). Sporangial production was observed until 23 June but not on 24 and 25 June, even though night-time conditions of temperature and humidity were similar to those of the previous days. Similarly, in sporulation period XIII (Table 4), the production of sporangia stopped after 5 days, on 16 October, even though favorable conditions for sporulation repeatedly occurred on 17 and 18 October (Fig. 4B). Sporulation period XIV (Table 4) was 9 days long (7 to 15 June) and produced no sporangia on 16 and 17 June. However, sporangia were produced on 16 June on the lesions caused by the inoculation on 3 June (sporulation period XV) (Table 4). Sporulation period XV was only 2 days long (15 and 16 June); rainfall was $136.2 \mathrm{~mm}$ between 15 and 17 June 2010.

At the beginning of the sporulation period, $21.0 \pm 5.6 \%$ of the lesion area was sporulating. This percentage did not vary in the following days, with an overall mean of $18.7 \pm 2.2 \%$. The cumulative number of sporangia produced per square millimeter of lesion increased at a high rate in the first 4 days of the sporulation period but at a lower rate in the following days (Fig. 5). Regression of the cumulative relative sporulation $(Y)$ observed during an event against the duration of the sporulation period in days $(X)$ yielded equation $Y=1-(1-0.123) e^{(-0.427 X)}$, with standard error of \pm 0.096 and \pm 0.041 for the two parameters $(0.123$ and 0.427 , respectively) and $R^{2}=0.97$.

Total numbers of sporangia produced per square millimeter of a downy mildew lesion over the entire infectious period ranged from 382 to 2.7 million (periods XII and XV, respectively). Numbers of conidia produced per square millimeter of lesion decreased as the lesion size increased $(P=0.29, r=-0.56, n=$ 15) whereas the duration of the infectious period was not related to numbers of sporangia produced $(P=0.65)$.

The average percentage of harvested sporangia that germinated in vitro was 35.5 to $68.0 \%(51.7 \pm 3.1 \%)$, depending on the

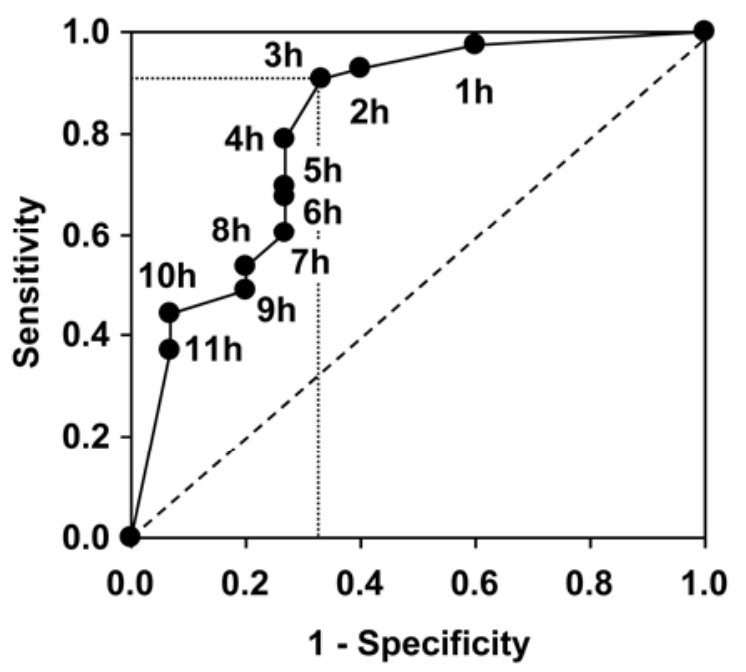

Fig. 3. Sensitivity versus 1-specificity for different cut-off points of the number of dark moist hour periods preceding the observation of sporulating downy mildew lesions in two vineyards of North Italy in 2008 to 2010. Numbers inside the plot are the cut-off points. Vertical and horizontal dotted lines show the coordinates of the best cut-off point. The dotted line shows the no-information line.

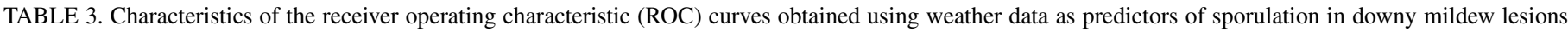
on leaves in two vineyards in North Italy in 2008 to 2010

\begin{tabular}{|c|c|c|c|c|}
\hline Weather variables ${ }^{\mathrm{a}}$ & AUROC $^{\mathrm{b}}$ & s.e. ${ }^{\mathrm{c}}$ & $P^{\mathrm{d}}$ & $95 \%$ Confidence interval ${ }^{\mathrm{e}}$ \\
\hline Average $\mathrm{T}$ & 0.585 & 0.089 & 0.33 & $0.411-0.759$ \\
\hline Maximum $\mathrm{T}$ & 0.587 & 0.089 & 0.32 & $0.412-0.762$ \\
\hline Minimum $\mathrm{T}$ & 0.613 & 0.088 & 0.19 & $0.442-0.785$ \\
\hline Average $\mathrm{RH}$ & 0.579 & 0.097 & 0.37 & $0.390-0.769$ \\
\hline Total rainfall & 0.675 & 0.076 & 0.045 & $0.525-0.825$ \\
\hline Wetness duration & 0.662 & 0.095 & 0.06 & $0.476-0.848$ \\
\hline Vapor pressure deficit & 0.595 & 0.090 & 0.28 & $0.418-0.772$ \\
\hline Hours with $\mathrm{RH} \geq 80 \%$ & 0.647 & 0.097 & 0.09 & $0.458-0.837$ \\
\hline Hours with $\mathrm{RH} \geq 85 \%$ & 0.557 & 0.092 & 0.52 & $0.376-0.737$ \\
\hline Hours with $\mathrm{RH} \geq 90 \%$ & 0.593 & 0.091 & 0.29 & $0.414-0.772$ \\
\hline Moist hours in the dark ${ }^{\mathrm{f}}$ & 0.816 & 0.071 & $<0.001$ & $0.677-0.955$ \\
\hline
\end{tabular}

a Weather variables were calculated in the time period between two field assessments; $\mathrm{T}=$ air temperature and $\mathrm{RH}=$ relative humidity.

b Area under the ROC curve.

c Standard error of AUROC.

d Probability level that AUROC is different from 0.5

e The $95 \%$ confidence interval for AUROC.

${ }^{f}$ Number of hours in the dark (i.e., between 8:00 p.m. and 7:00 a.m.) with $\mathrm{RH} \geq 80 \%$, or rain $>0$ mm, or wetness duration $>30$ min. 
sporulation period. Germination was as high as 80 to $90 \%$ on some days. The percentage of germination was not related to the number of sporangia produced $(P=0.55)$.

Sporangia were found on lesions over a wide range of weather conditions. For instance, sporulation period XIII (Table 4) was cold and dry (average temperature $=11.1^{\circ} \mathrm{C}$, range 5.1 to $18.2^{\circ} \mathrm{C}$; minimum $\mathrm{RH}=25.6 \%$; and no rainfall); sporulation period $\mathrm{V}$ was cool and moist (average temperature $=15.5^{\circ} \mathrm{C}$, range 12.5 to $19.3^{\circ} \mathrm{C}$; minimum $\mathrm{RH}=64.8 \%$; and $49.5 \mathrm{~mm}$ rainfall); and sporulation period III was warm and dry (average temperature $=26.9^{\circ} \mathrm{C}$, range 14.2 to $32.8^{\circ} \mathrm{C}$; minimum $\mathrm{RH}=40.3 \%$; and $14.2 \mathrm{~mm}$ of rain). The number of sporangia was negatively correlated with maximum temperature $(P=0.02, r=-0.60, n=15)$ and positively correlated with all the variables related to humidity of the sporu-

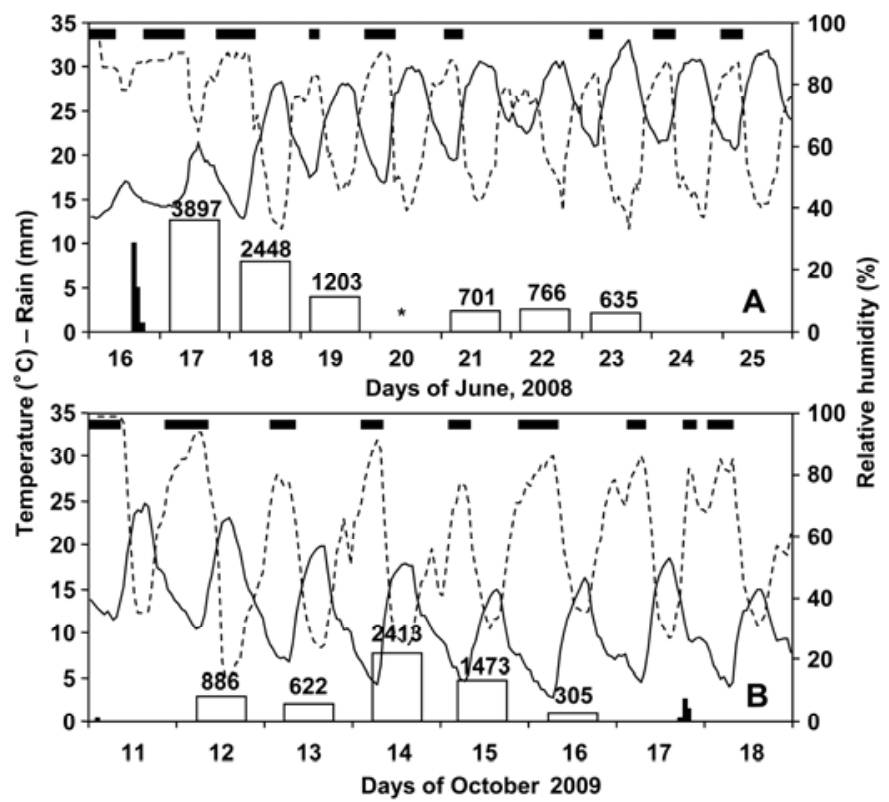

Fig. 4. Relationship between air temperature $\left({ }^{\circ} \mathrm{C}\right.$, full line), relative humidity (\%, dotted line), rainfall (mm, black bars), moist hours in the dark (black squares), and number of Plasmopara viticola sporangia produced per square millimeter of downy mildew lesion (white bars and numbers) in the Grugliasco vineyard (North Italy) between A, 16 and 25 June 2008 and B, 11 and 18 October 2002; an asterisk (*) represents a missing value. lation period, particularly average RH $(P=0.001, r=0.78, n=$ $15)$ and the ratio of hours with $\mathrm{RH} \geq 80 \%(P<0.001, r=0.82$, $n=15)$ or moist hours in the dark $(P<0.001, r=0.80, n=15)$. Therefore, the number of sporangia produced by a lesion over the whole infectious period increased as the maximum temperature of the period decreased and as humidity increased (Fig. 6).

Release of sporangia. Sporangia of $P$. viticola were detected in the air on 271 of 297 days (91.2\%). Sporangia were caught over a wide range of weather conditions (Table 5); rainfall occurred on $26 \%$ of the days when sporangia were trapped. Numbers of the airborne sporangia was 0.1 to 732 sporangia $/ \mathrm{m}^{3}$ of air per day, with a median of 3.6 sporangia $/ \mathrm{m}^{3}$ of air per day. Fewer than 21 sporangia $/ \mathrm{m}^{3}$ of air were sampled per day in approximately $90 \%$ of the cases, and the number exceeded 50 sporangia $/ \mathrm{m}^{3}$ of air per day in only $3 \%$ of the cases (Fig. 7).

Specific weather conditions were not associated with the daily number of airborne sporangia. For instance, in September 2010 at Piacenza (Fig. 8), 978 sporangia $/ \mathrm{m}^{3}$ of air were cumulatively trapped over 3 days after the rain period of 7 to 9 September (38.4 mm of rain) but only 16 sporangia $/ \mathrm{m}^{3}$ of air were cumu-

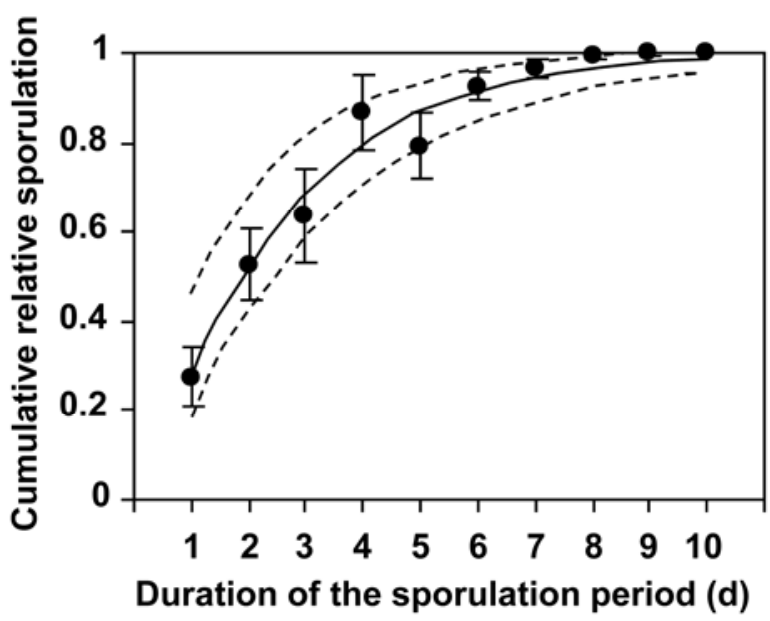

Fig. 5. Cumulative relative number of Plasmopara viticola sporangia produced on downy mildew lesions over a sporulation period. Black dots are averages and whiskers are \pm standard errors of the 15 sporulating periods of Table. The line is the fit of data with the equation $Y=1-(1-0.123) e^{(-0.427 X)}$, $R^{2}=0.97$; dotted lines show the $95 \%$ confidence band of the equation.

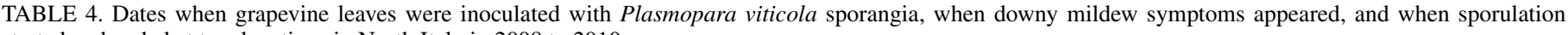
started and ended at two locations in North Italy in 2008 to 2010

\begin{tabular}{|c|c|c|c|c|c|c|}
\hline Location, year & Sporulation period & Inoculation $^{\mathrm{a}}$ & Symptom onset & Start of sporulation ${ }^{b}$ & End of sporulation ${ }^{c}$ & Infectious period $^{\mathrm{d}}$ \\
\hline \multirow[t]{3}{*}{ Piacenza 2008} & I & 28 May & 3 June & 11 June & 17 June & 7 \\
\hline & II & 11 June & 16 June & 17 June & 22 June & 6 \\
\hline & III $^{\mathrm{e}}$ & $\ldots$ & $\ldots$ & 26 June & 1 July & 6 \\
\hline \multirow[t]{2}{*}{ Piacenza 2010} & IV & 8 June & 14 June & 17 June & 23 June & 7 \\
\hline & V & 23 September & 26 September & 27 September & 5 October & 9 \\
\hline \multirow[t]{2}{*}{ Grugliasco 2008} & VI & 13 May & 19 May & 5 June & 11 June & 7 \\
\hline & $\mathrm{VII}^{\mathrm{e}}$ & $\ldots$ & $\ldots$ & 17 June & 23 June & 7 \\
\hline \multirow[t]{6}{*}{ Grugliasco 2009} & VIII & 11 May & 14 May & 19 May & 28 May & 10 \\
\hline & $\mathrm{IX}^{\mathrm{e}}$ & $\ldots$ & $\ldots$ & 1 June & 3 June & 3 \\
\hline & $\mathrm{X}^{\mathrm{e}}$ & $\ldots$ & $\ldots$ & 10 June & 17 June & 8 \\
\hline & $\mathrm{XI}$ & 25 May & 1 June & 3 June & 11 June & 9 \\
\hline & $\mathrm{XII}^{\mathrm{e}}$ & $\ldots$ & $\ldots$ & 17 June & 23 June & 7 \\
\hline & XIII & 2 October & 8 October & 12 October & 16 October & 5 \\
\hline \multirow[t]{2}{*}{ Grugliasco 2010} & XIV & 20 May & 27 May & 7 June & 15 June & 9 \\
\hline & XV & 3 June & 09 June & 15 June & 16 June & 2 \\
\hline
\end{tabular}

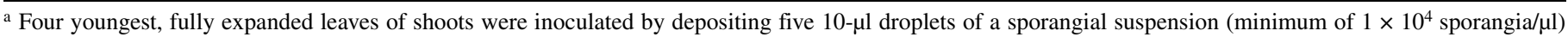
per leaf; after inoculation, leaves were placed in moist plastic bags for $12 \mathrm{~h}$ to favor infection.

${ }^{b}$ First day after inoculation when white, fresh mildew appeared in downy mildew lesions.

${ }^{c}$ Last day when sporulation was observed in downy mildew lesions.

d Number of days with sporulation.

e In these cases, sporulation was observed in a second or third sporulation period. 
latively caught over the 3 days after day rain period of 18 and 19 September (4.2 mm of rain). On 11 September, 732 sporangia $/ \mathrm{m}^{3}$ of air were caught with an average temperature and $\mathrm{RH}$ of $19^{\circ} \mathrm{C}$ and $61.8 \%$, respectively. Fewer sporangia were caught with simi-
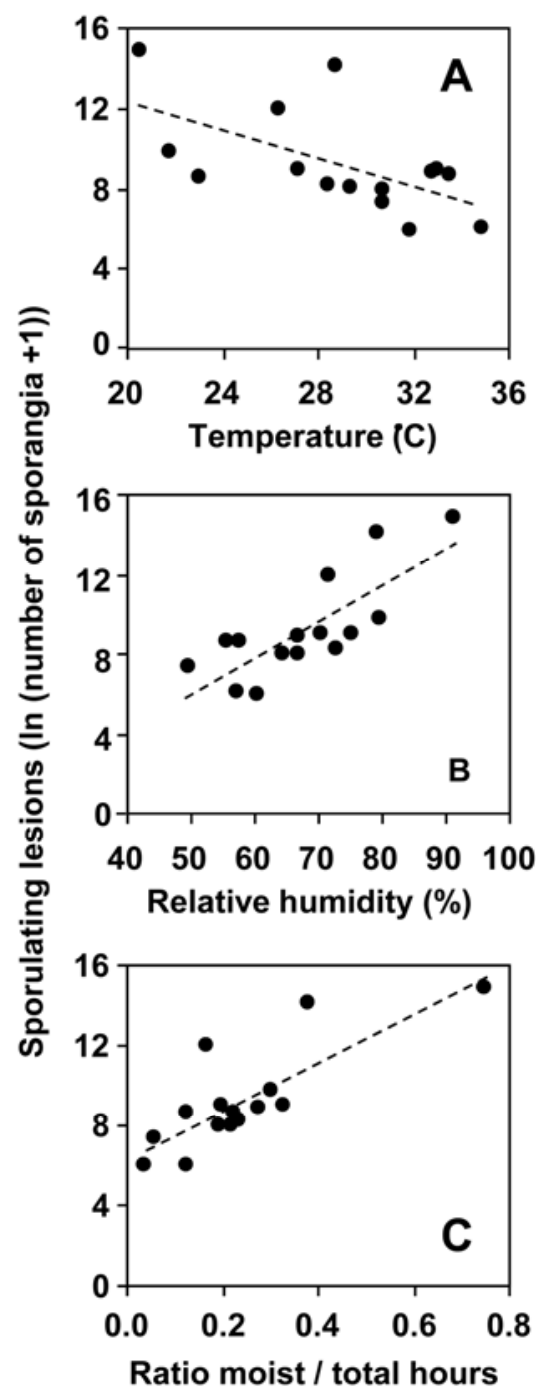

Fig. 6. Relationship between $\mathbf{A}$, maximum temperature $\left({ }^{\circ} \mathrm{C}\right)$; $\mathbf{B}$, average relative humidity; or $\mathbf{C}$, ratio of number of moist hours in the dark to total hours and the natural logarithm of the cumulative number of Plasmopara viticola sporangia produced on downy mildew lesions during the 15 sporulation periods of Table 3. Dotted lines are the fit of data with the following equations: A, $Y=-0.35 X+19.3, R^{2}=0.35 ; \mathbf{B}, Y=0.18 X-3.2, R^{2}=0.60$; and C, $Y=6.31 X+12.1, R^{2}=0.64$, where $Y$ is the natural logarithm of the cumulative number of sporangia. lar temperatures but either moister (39 sporangia $/ \mathrm{m}^{3}$ of air on 6 September, with $19.5^{\circ} \mathrm{C}$ and $\left.72.1 \% \mathrm{RH}\right)$ or dryer (8 sporangia/ $\mathrm{m}^{3}$ of air on 1 September, with $18.8^{\circ} \mathrm{C}$ and $\left.43.5 \% \mathrm{RH}\right)$ conditions.

The 26 days on which the spore sampler did not catch sporangia were randomly distributed within the sampling periods, and the weather conditions on these days were similar to those when sporangia were caught (Table 5). For instance, in September 2010 at Piacenza (Fig. 8), no sporangia were caught on 2 to 5, 17, and 30 September.

Sporangia were caught in 1,816 of the 3,514 (51.7\%) 2-h periods considered; $54 \%$ of these periods when sporangia were trapped were in daylight versus $46 \%$ in the dark. No diurnal pattern of airborne sporangia concentration was detected, and the daily change in number of airborne sporangia was not related to specific weather conditions (Fig. 9).

\section{DISCUSSION}

Sporulation of downy mildew lesions occurred frequently under the vineyard conditions of this study (sporulation was detected in $75.9 \%$ of the assessments, and $23.8 \%$ of all lesions sporulated). Frequency of sporulation across populations of lesions was positively correlated with the number of moist hours in the preceding dark period. In an ROC analysis, prediction of sporulation based on the occurrence of $\geq 3$ moist hours at night provided overall accuracy of 0.85 . This result fulfills the lack of knowledge mentioned by Gilles in 2004 (17).

Gilles (17) reviewed works published on sporulation of $P$. viticola, most of them carried out in controlled conditions: leaves

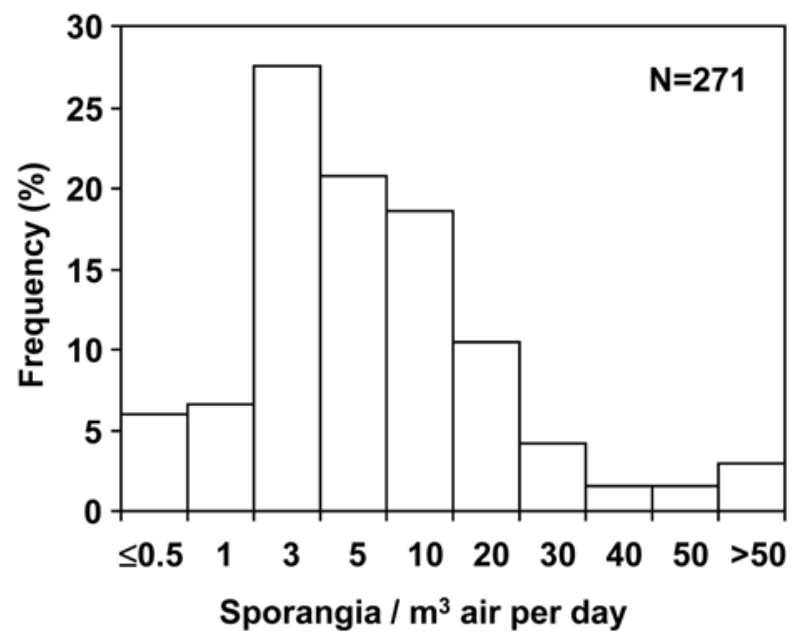

Fig. 7. Frequency distribution of numbers of Plasmopara viticola sporangia sampled from the air near grapevine plants with sporulating downy mildew lesions during 271 days at two locations of North Italy in 2009 and 2010.

TABLE 5. Weather data recorded over a 295-day period when airborne sporangia of Plasmopara viticola were trapped or not trapped by spore samplers placed near grapevine plants with sporulating downy mildew lesions

\begin{tabular}{|c|c|c|c|c|c|c|}
\hline \multirow[b]{2}{*}{ Weather variables } & \multirow[b]{2}{*}{ Presence of sporangia ${ }^{a}$} & \multicolumn{4}{|c|}{ Variables $^{\mathrm{b}}$} & \multirow[b]{2}{*}{$P^{\mathrm{c}}$} \\
\hline & & Average & s.d. & Max & Min & \\
\hline Temperature $\left({ }^{\circ} \mathrm{C}\right)$ & No & 18.8 & 4.8 & 27.4 & 8.8 & 0.07 \\
\hline Relative humidity (\%) & Yes & 67.3 & 12.2 & 96.9 & 25.9 & \\
\hline \multirow[t]{2}{*}{ Rain (mm) } & No & 3.0 & 9.6 & 45.5 & 0 & 0.70 \\
\hline & Yes & 2.3 & 8.6 & 102.4 & 0 & . \\
\hline
\end{tabular}

a There were 26-day periods with no sporangia caught and 269-day periods of sampling.

${ }^{\mathrm{b}}$ Average, standard deviation (s.d.), minimum, and maximum refer to the weather variables.

c Probability level of the $t$ test for differences between the two groups (no or yes). 
with lesions were moved to environments with regulated light, temperature, and humidity, and the sporulation course was analyzed over time. Gilles (17) considered that sporangiophores are produced over a wider range of conditions than sporangia (26) and are not inhibited by light (42). He then concluded that the minimum duration of high humidity required for sporangia production in a vineyard may be shorter than the minimum duration reported in the literature; sporangiophores can emerge even when conditions are not favorable for sporangia production and, when conditions become favorable, these preexisting sporangiophores can produce sporangia rapidly.

Gilles (17) also stated that investigations of sporulation under vineyard conditions would provide valuable information for forecasting models. The disease models of Magnien et al. (28), Park et al. (35), and Orlandini et al. (33) were all based on previous sporulation studies carried out under controlled environment

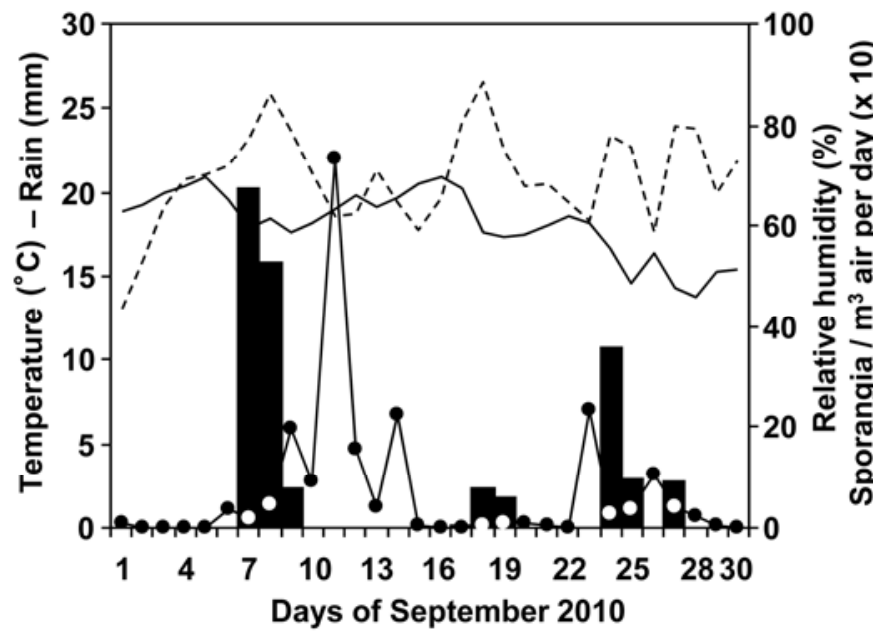

Fig. 8. Air temperature $\left({ }^{\circ} \mathrm{C}\right.$, line), relative humidity (\%, dotted line), rainfall (mm, black bars), and cumulative numbers of Plasmopara viticola sporangia (line with circles) sampled per day from the air near grapevine plants with sporulating downy mildew lesions. Example for the vineyard of Grugliasco (North Italy) in September 2010. conditions and the assumption that sporulation is expected when $\mathrm{RH}$ is 95 to $100 \%$ during at least $4 \mathrm{~h}$ in darkness (36). These models consider that at least 4 to $7 \mathrm{~h}$ (depending on the model) with $>90 \% \mathrm{RH}$ are required for sporulation; in the last two models, only dark periods are considered. In the present study, the use of a threshold of $\mathrm{RH}>90 \%$ did not correctly predict sporulation, whereas a threshold of at least 3 moist hours in the dark was a reliable predictor. Therefore, this threshold for moist hours in the dark could replace numbers of hours with $\mathrm{RH}>90 \%$ in the above models.

This work provides original data on the sporulation dynamics of $P$. viticola over a single sporulation period in the absence of washing rain. Previous studies focused on studying sporulation on lesions which had been washed with water and inducing sporulation $(19,22,45)$. In this study, once a lesion began to sporulate, sporangia were produced at a high rate for the first 4 days and then at a lower rate until sporulation stopped. The time course of cumulative sporangia production per unit surface area of a lesion followed a monomolecular growth model. This temporal sporulation pattern is similar to the shape of normalized sporulation curves usually used in disease growth models (43). Lesions of other downy mildews also remain infectious for some days $(9,14,40)$. The duration of single sporulation periods was 2 to 10 days, and we could not detect any specific weather conditions that could explain why a lesion stopped sporulating. In other downy mildews, sporulation was related to the nutrient status of the lesion $(25,37)$. Sporangiophores and sporangia are rich in glucans, particularly in septa (23), and, therefore, their production requires substantial carbohydrates $(5,37)$. Chlorotic lesions of $P$. viticola bear no photosynthetic activity (32) and, therefore, the carbohydrate supply in the lesion can only support sporulation for short periods; in addition, the supply of nutrients from the surrounding green tissue may be low because photosynthesis in these tissues is also reduced (7). The duration of sporulation in $P$. viticola also could be related to the nutrient status of the leaf tissue supporting sporulation rather than to weather conditions; however, this aspect needs further investigations.

In this work, the total number of sporangia produced per unit of lesion area increased with humidity during the sporulation period. The number of dark moist hours during the sporulation period
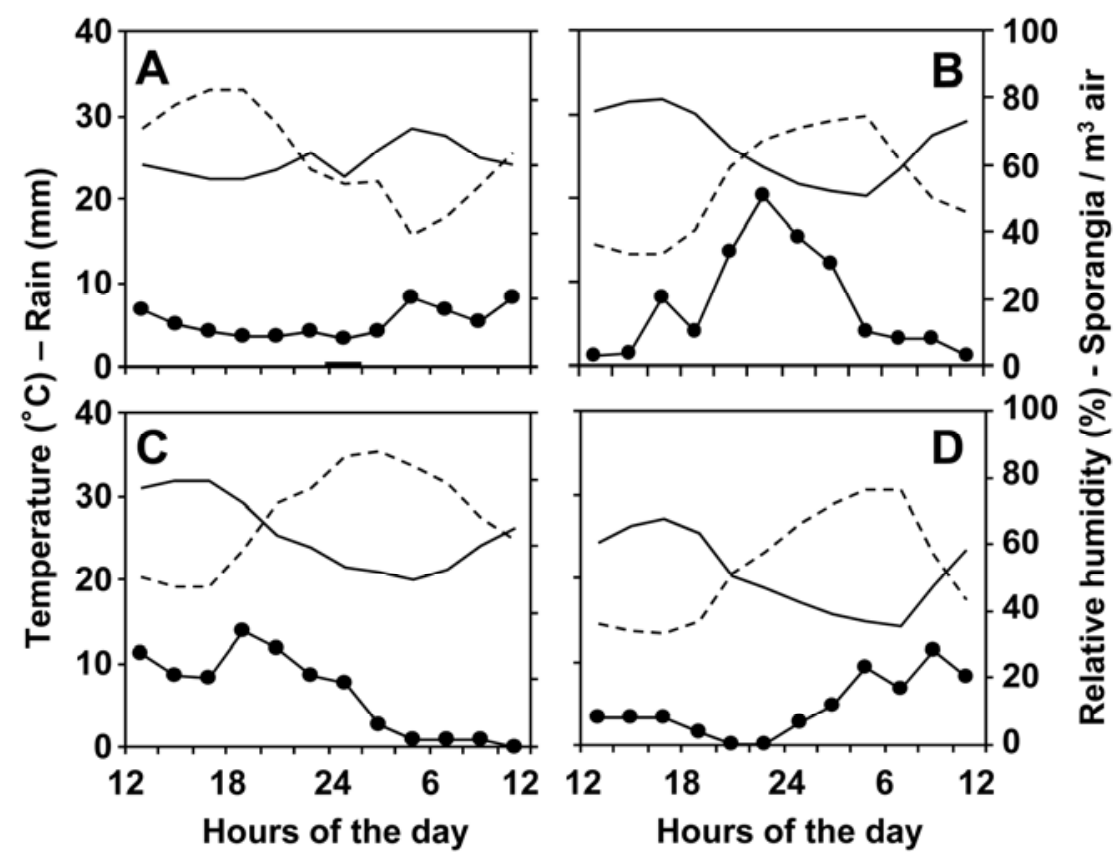

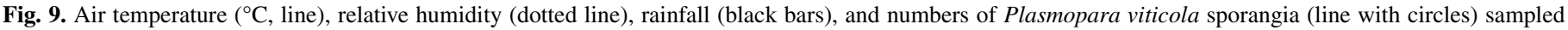

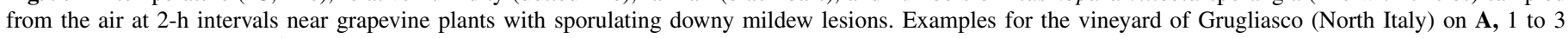
August; B, 5 and 6 August; C, 13 and 14 August; and D, 7 and 8 September 2010. 
explained $64 \%$ of variability in the number of sporangia produced. Number of sporangia also decreased with increases in maximum temperatures. That production of sporangia by $P$. viticola requires high humidity has been previously documented (20, 24,38 ), as well as the detrimental effects of temperatures $>30^{\circ} \mathrm{C}$ $(2,20,31)$, but no quantitative relationships between the production of sporangia and humidity or temperature had been reported.

Once formed, sporangia are released. It is commonly assumed that infection requires a rain event to dislodge the sporangia from their sporangiophores and provide the surface moisture necessary for zoospore release and motility (16). Previous work showed that sporangia are only released during rainfall events $(3,21)$ and that airborne sporangia are abundant during rainy periods $(1,4,8$, $12,13,15,29,34)$. In the current work, in which sporulating downy mildew lesions provided a constant source of sporangia, sporangial release was observed over a wide range of weather conditions, including dry periods. Therefore, rainfall does not seem to be a triggering factor for secondary infections, because the surface wetness for zoospore release and motility can be generated by dew. The close relationship between rainfall and the numbers of airborne $P$. viticola sporangia reported in other studies may have been caused by variable numbers of sporulating lesions triggered by rainy periods rather than by conditions that limit or favor sporangial release. On the other hand, the numbers of airborne $P$. viticola sporangia followed inconsistent diurnal patterns in previous studies $(10,15,21,34)$, as in the current research. These inconsistent diurnal patterns can be explained by the mechanism of detachment of sporangia from the sporangiophores; detachment requires moisture for the dissolution of a cross-wall of callus, moisture that can be provided by rainfall, $\mathrm{RH}$, or dew $(11,30)$.

In conclusion, this work provides new information on in situ production and release of $P$. viticola sporangia under vineyard conditions and influence of environmental conditions on sporulation. This information should be helpful in refining epidemiological models used as decision aids in grape downy mildew management programs.

\section{ACKNOWLEDGMENTS}

This work was carried out as part of the MoMaViP project, founded by the Piedmont Region, Italy, and T. Caffi carried out part of this work within the Doctoral School on the Agro-Food System (Agrisystem) of the Università Cattolica del Sacro Cuore (Italy). We thank F. Spanna (Settore Fitosanitario, Piedmont Region, Italy) for coordinating the work and S. Savary for the critical review of the manuscript.

\section{LITERATURE CITED}

1. Albelda, Y., Rodríguez-Rajo, F. J., Jato, V., and Aira, M. J. 2005. Concentraciones atmosféricas de propágulos fúngicos en viñedos del Ribeiro (Galicia. España). Bol. Mycol. 20:1-8.

2. Arens, K. 1929. Untersuchungen über Keimung und Zytologie der Oosporen von Plasmopara viticola (Berl. et De Toni). Jahrb. Wiss. Bot. 70:57-92.

3. Blaeser, M., and Weltzien, H. C. 1978. The importance of sporulation, dispersal, and germination of sporangia of Plasmopara viticola. J. Plant Dis. Prot. 3:155-161

4. Braumberger, L. 1997. Investigations on sampling spores of Plasmopara viticola and Uncinula necator using Burkard spore traps. Vitic. Enol. Sci. 52:131-132.

5. Brema, S., Rasta D. M., and Ruffnera, H. P. 1986. Partitioning of photosynthate in leaves of Vitis vinifera infected with Uncinula necator or Plasmopara viticola. Physiol. Mol. Plant Pathol. 29:285-291.

6. Brooke, P. J. 1979. Effect of light on sporulation of Plasmopara viticola. N. Z. J. Bot. 17:135-138.

7. Caffi, T., Legler, S. E., Rossi, V., and Poni, S. 2010. Photosynthetic activity in grape leaf tissue with latent, visible and 'virtual' downy mildew lesions. Page 204 in: Proc. 6th Int. Workshop Grapevine Downy and Powdery Mildew. Bordeaux, France.

8. Chavarria, G., Pessoa dos Santos, H., Fin, E., Sonego, O. R., Garrido, L. R., and Marodin, G. A. B. 2006. Dispersao anemofila de esporangio- sporos de Plasmopara viticola em cultivos protegido e convencional de videira. Rev. Bras. Fructicult. 31:710-717.

9. Cohen, Y. 1977. The combined effects of temperature, leaf wetness, and inoculum concentration on infection of cucumbers with Pseudoperonospora cubensis. Can. J. Bot. 55:1478-1487.

10. Corbaz, R. 1972. Etudes des spores fongiques captées dans 1'air. Phytopathol. Z. 74:318-328

11. Cornu, M. 1882. Etudes sur les Péronosporées (avec historique detaillé). Academie des Sciences, Paris, Gauthier-Villars Imp., 80p., 5 pl. et Recueil des Savants etrangers Acad. des Sciences, 1-10. GautheierVillars, Paris.

12. Díaz, M. R., Iglésias, I., and Jato, V. 1997. Airborne concentrations of Botrytis, Uncinula and Plasmopara spores in a vineyard in Leiro-Ourense (N.W. Spain). Aerobiologia 13:31-35.

13. Díaz, M. R., Iglesias, I., and Jato, V. 1998. Seasonal variation of airborne fungal spore concentrations in a vineyard of northwest Spain. Aerobiologia 14:221-227.

14. Dickinson, C. H., and Singh, H. 1982. Colonization and sporulation of Peronospora viciae on cultivars of Pisum sativum. Plant Pathol. 31:333341.

15. Fernandez-Gonzalez, M., Rodriguez-Rajo, J., Jato, V., and Aira, J. 2009. Incidence of fungals in a vineyard of the denomination of origin ribeiro (Ourense-north-western Spain). Ann. Agric. Envrion. Med. 16:263-271.

16. Gessler, C., Pertot, I., and Perazzolli, M. 2011. Plasmopara viticola: A review of knowledge on downy mildew of grapevine and effective disease management. Phytopathol. Mediterr. 50:3-44.

17. Gilles, T. 2004. Forecasting downy mildew diseases. Pages 2, 3-67 in: Advances in Downy Mildew Research. P. Spencer-Phillips and M. Jeger, eds. Kluwer Academic Publisher, Dordrecht, The Netherlands.

18. Hanley, J. A. 2005. Receiver operating characteristic (ROC) curves. In: Encyclopedia of Biostatistics, 2nd ed. John Wiley and Sons, New York.

19. Hill, G. K. 1989. Effect of temperature on sporulation efficiency of oilspots caused by Plasmopara viticola (Berk. \& Curt. ex de Bary) Berl. $\&$ de Toni in vineyards. Wein Wiss. 44:86-90.

20. Istvantti, G., and Palinkas, G. 1913. Etudes sur le mildiou de la vigne. Inst. Centr. Ampel. R. Hong. Ann. 4:1-125.

21. Kast, W. K. 1997. A spore-trap for collecting infectious sporangia of downy mildew. Wein Wiss. 52:163-164.

22. Kennelly, M. M., Gadoury, D. M., Wilcox, W. F., Magarey, P. A., and Seem, R. C. 2007. Primary infection, lesion productivity, and survival of sporangia in the grapevine downy mildew pathogen Plasmopara viticola. Phytopathology 97:512-522.

23. Kortekamp, A. 2005. Growth, occurrence and development of septa in Plasmopara viticola and other members of the Peronosporaceae using light- and epifluorescence-microscopy. Mycol. Res. 109:640-648.

24. Lalancette, N., Ellis, M. A., and Madden, L. V. 1988. A quantitative model for describing the sporulation of Plasmopara viticola on grape leaves. Phytopathology 78:1316-1321.

25. Lebeda, A., and Cohen, Y. 2011. Cucurbit downy mildew (Pseudoperonospora cubensis)—biology, ecology, epidemiology, host-pathogen interaction and control. Eur. J. Plant Pathol. 129:157-192.

26. Leu, L. S., and Wu, H. G. 1982. Inoculation, sporulation and sporangial germination of grape downy mildew fungus, Plasmopara viticola. Plant Prot. Bull. (Taiwan) 24:161-170.

27. Levene, H. 1960. Robust tests for equality of variances. Pages 278-292 in: Contributions to Probability and Statistics: Essays in Honor of Harold Hotelling. I. Olkin, S. G. Ghurye, W. Hoeffding, W. G. Madow, and H. B. Mann, eds. Stanford University Press, Stanford.

28. Magnien, C., Jacquin, D., Muckensturm, N., and Guillemard, P. 1991. MILVIT: A descriptive quantitative model for the asexual phase of grapevine downy mildew. IOBC/WPRS Bull. 21:451-459.

29. Magyar, D., Frenguelli, G., Bricchi, E., Tedeschini, E., Csontos, P., Li, D. W., and Bobvos, J. 2009. The biodiversity of air spora in an Italian vineyard. Aerobiologia 25:99-109.

30. Mangin, L. 1891. Sur la desarticulation des conidies chez les Peronosporées. Soc. Bot. France Bul. 38:176-184, 232-236.

31. Muller, K., and Sleumer, H. 1934. Biologische Unterschungen über die Peronosorakrankheit des Weinstokes mit besonderer Breücksichtingung threr Bekämpfung nach der Inkhationskalendermethode. Landwirtsch. Jahrb. 79:509-576.

32. Orlandini, S., and Giuntoli, A. 1998. Photosynthesis of grapevine leaves infected by downy mildew. J. Int. Sci. Vigne Vin 32:121-127.

33. Orlandini, S., Massetti, L., and Marta, A. 2008. An agrometeorological approach for the simulation of Plasmopara viticola. Comput. Electron. Agric. 64:149-161.

34. Paredes, M. M., Martínez, J., F., Silva, I., Tormo, R., and Muñoz, A. F 1998. Dinámica de dispersión de esporangios de Plasmopara en Badajoz. Pages 91-96 in: XIX Jornadas de Viticultura y Enología, Tierra de Barros, Cultural Santa Ana.

35. Park, E. W., Seem, R. C., Gadoury D. M., and Pearson, R. C. 1997. 
DMCAST: A prediction model for grape downy mildew development. Wein Wiss. 52:182-89.

36. Pearson, R. C., and Goheen, A. C. 1988. Compendium of Grape Diseases. American Phytopathological Society, St. Paul, MN.

37. Perl, M., Cohen, Y., and Rotem, J. 1972. The effect of humidity during darkness on the transfer of assimilates from cucumber leaves to sporangia of Pseudoperonospora cubensis. Physiol. Plant Pathol. 2:113-122.

38. Ravaz, L. 1914. Traité général de viticulture. Pages 282-322 in: III Partie: Le Mildiou. Broché, Montpellier, Paris.

39. Rossi, V., Giosuè, S., and Caffi, T. 2009. Modelling the dynamics of sexual and asexual spores during Plasmopara viticola epidemics. J. Plant Pathol. 91:615-627.

40. Rotem, J., and Cohen, Y. 1971. Relativity of limiting and optimum inoculum loads, wetting durations, and temperatures for infection by Phytophthora infestans. Phytopathology 61:275-278.
41. Rotem, J., Cohen, Y., and Bashi, E. 1978 Host and environmental influences on sporulation in vivo. Annu. Rev. Phytopathol. 16:83-101.

42. Rumbolz, J., Wirtz, S., Kassemeyer, H. H., Guggenheim, R., Schäfer, E., and Büche, C. 2002. Sporulation of Plasmopara viticola: Differentiation and light regulation. Plant Biol. 4:413-422.

43. Segarra, J., Jeger, M. J., and van den Bosch, F. 2001. Epidemic dynamics and patterns of plant diseases. Phytopathology 91:1001-1010.

44. Yarwood, C. E. 1937. The relation of light to the diurnal cycle of sporulation of certain downy mildews. J. Agric. Res. 54:365-373.

45. Zachos, D. G. 1959. Recherches sur la biologie et l'epidemiologie du mildiou de la vigne en Grece. Ann. Inst. Phytopathol. Benaki 2:193-335. (In French)

46. Zweig, M. H., and Campbell, G. 1993. Receiver-operating characteristic (ROC) plots: A fundamental evaluation tool in clinical medicine. Clin. Chem. 39:561-577. 